\section{Intra-ampullary protruding mass: unusual presentation of mucinous carcinoma of the}

\section{pancreas}
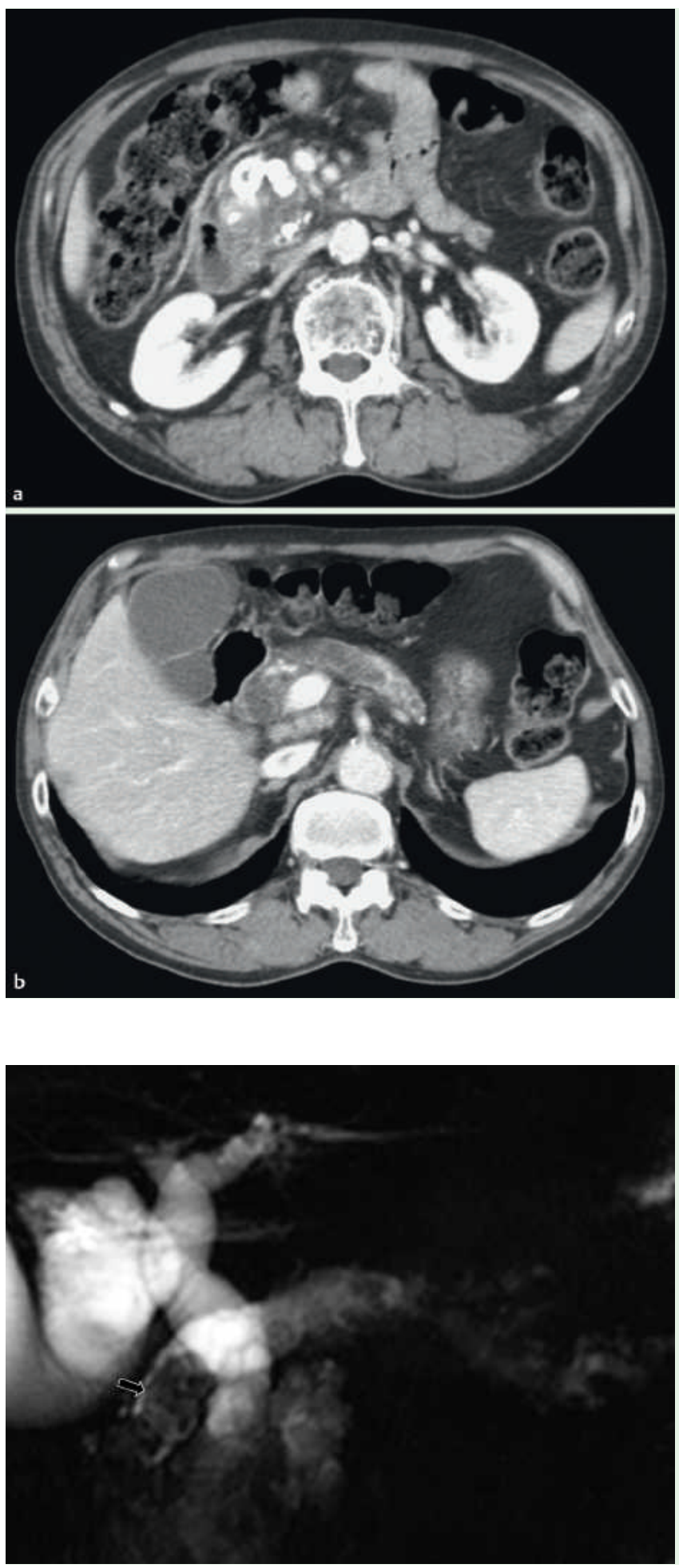

Fig. 1 a Abdominal computed tomography scan shows enlarged pancreas head with multiple calcifications. b Upstream pancreatic duct is dilated with a parenchymal atrophy.

Fig. 2 Magnetic resonance cholangiopancreatography shows multiple filling defects in the dilated pancreatic duct. A large stone is noted at the proximal part of the pancreatic duct (arrow).
A 71-year-old man was referred to our hospital with chronic alcoholic pancreatitis. He had a history of daily intake of alcohol and intermittent abdominal pain over the past 15 years. The biochemical tests were normal except for a mild increase in the gamma glutamyl transpeptidase level. Cancer antigen (CA) 19-9 was $118.1 \mathrm{U} / \mathrm{mL}$ (normal value $<27 \mathrm{U} / \mathrm{mL}$ ). Abdominal computed tomography scan showed an enlarged pancreatic head with calcifications, a marked dilated upstream pancreatic duct, and parenchymal atrophy ( $\bullet$ Fig. 1 a and $\odot$ Fig. 1 b).

Magnetic resonance cholangiopancreatography also revealed intraductal filling defects in the dilated pancreatic duct (๑ Fig. 2). Under the impression of chronic pancreatitis with massive pancreaticolithiasis, endoscopic retrograde cholangiopancreatography was performed. The major papilla was slightly enlarged, and yellowish mucin-like material was noted at the orifice ( $\bullet$ Fig. $3 a$ ). We initially thought that this material might be bile-tinged, fragmented pancreatic duct stones because the patient had a massive pancreaticolithiasis. However, endoscopic pancreatic sphincterotomy revealed it to be an intra-ampullary soft mass protruding from the pancreas head ( Fig. 3b). A biopsy was performed and the pathology revealed a mucinous carcinoma with well-defined pools of mucin and malignant epithelial cells ( $\bullet$ Fig. 4).

Mucinous carcinoma of the pancreas is rare and is characterized histologically by lakes of extracellular mucin with "floating" malignant epithelial cells. Grossly, the mass is gel-like, soft, and movable [1]. This characteristic pathologic finding, of the tumor in this case, might have affected the peculiar endoscopic finding and unusual location (i.e. the protruding mass in the ampullary portion of the papilla). Fortunately, we could diagnose the pancreatic cancer that had not been seen on the radiologic studies when performing the pancreatic sphincterotomy, which is known to be an essential step for endoscopic intervention of chronic pancreatitis, especially for stone removal [2].

Endoscopy_UCTN_Code_CCL_1AB_2AZ_3AB 

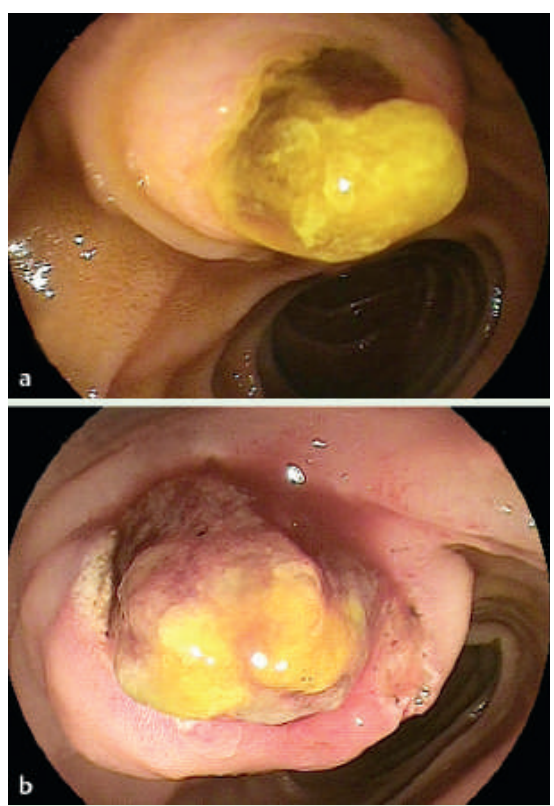

Fig. 3 a Duodenoscopy shows a bulging major papilla with yellowish, mucin-like material at the orifice. $\mathbf{b}$ After the pancreatic sphincterotomy, a reddish and friable soft mass is detected at the ampullary portion of the papilla.

\section{E. J. Lee' ${ }^{1}$, K. R. Joo ${ }^{1}$, J. M. Cha',}

H. P. Shin ${ }^{1}$, S. W. Jung ${ }^{1}$, J. I. Lee ${ }^{1}$,

G. Y. Kim²

${ }^{1}$ Department of Internal Medicine, Kyung Hee University East-West Neo Medical Center, Seoul, Korea

2 Department of Pathology, Kyung Hee University East-West Neo Medical Center, Seoul, Korea

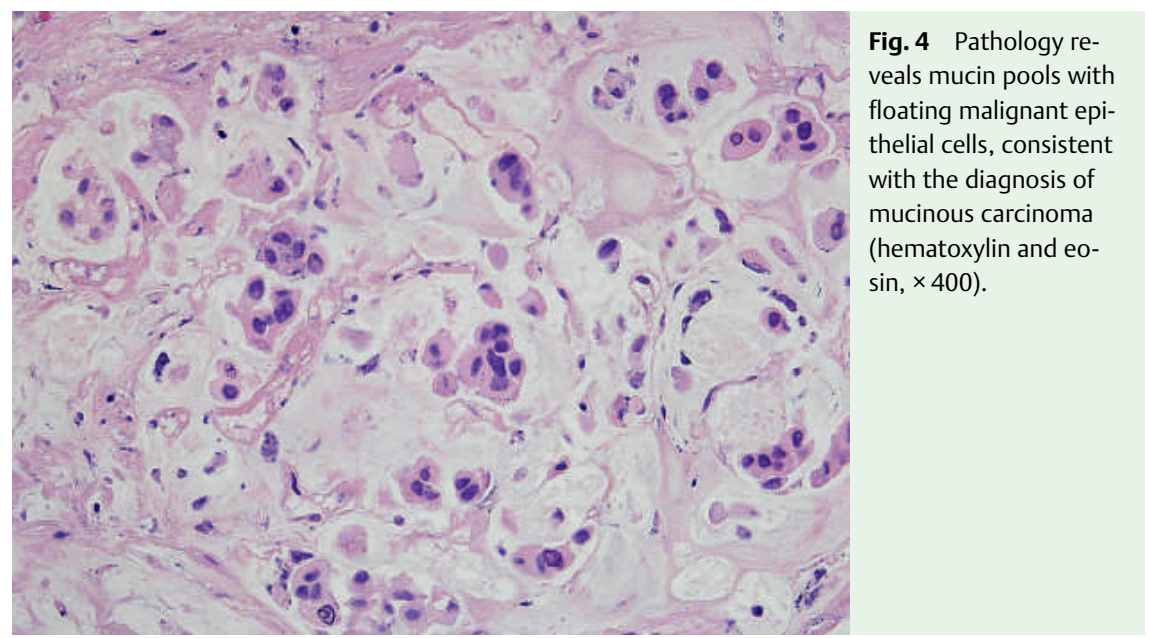

\section{References}

1 Adsay NV, Pierson C, Sarkar F et al. Colloid (mucinous noncystic) carcinoma of the pancreas. Am J Surg Pathol 2001; 25: 26 42

2 Attasaranya S, Abdel Aziz AM, Lehman GA. Endoscopic management of acute and chronic pancreatitis. Surg Clin North Am 2007; 87: 1379-1402
Bibliography

DOI 10.1055/s-0028-1119730

Endoscopy 2009; 41: E74 -E75

(c) Georg Thieme Verlag KG Stuttgart · New York . ISSN 0013-726X

\section{Corresponding author}

\section{K. R. Joo, MD}

Department of Internal Medicine Kyung Hee University East-West

Neo Medical Center

149 Sangil-dong Gangdong-gu

Seoul, 134-090

Korea

Fax: +82-2-4406295

krjoo@khu.ac.kr 